THE JOURNAL OF TEACHING ENGLISH FOR SPECIFIC AND ACADEMIC PURPOSES

Vol. 6, $\mathrm{N}^{\mathrm{o}}$ 2, Special Issue, 2018, pp. 235-243

UDC: $371.3+(004.738: 159.953): 811.111 \quad$ https://doi.org/10.22190/JTESAP1802235H

\title{
SOFT-SKILL BASED SYLLABUS IN LEGAL ENGLISH COURSES
}

\author{
Alena Hradilová \\ Language Centre of Masaryk University \\ Phone: +420608871940, E-Mail: alena.hradilova@law.muni.cz
}

\begin{abstract}
The article discusses reasons why a team of teachers at Language Centre of Masaryk University decided to abandon the traditional topic based syllabus in order to focus on soft skills and life skills. It offers an application of needs analyses carried out among faculty graduates to our course syllabi and its result in major changes to structuring the courses in terms of moving from topics as our starting point to life skills, and from atomized language exercises to task chaining. This approach leads to useful soft skills development where topics serve the purpose of soft-skill practice fillers and vocabulary building is a natural by-product of the activities. The paper offers examples of chained lesson plans based on experiential learning. Student feedback and a small-scale action research illustrates how they perceive and appreciate the changes and how the changed approach towards syllabus design influences their motivation to learn.
\end{abstract}

Key words: soft skills, task chaining, experiential learning, LSP, needs analysis

\section{INTRODUCTION}

Designing a syllabus for languages for specific purposes is one of LC teachers' reoccurring chores. LSP courses need to be tailored to both students, university and job market real needs. This places most of the ready-made general or ESP textbooks on a shelf of material for inspiration, rather than straight into student's hands, as no textbook seems to be just right for our particular purposes. This is why it has traditionally been the LSP teacher's responsibility to carry out a careful needs analysis in order to define target communicative situations specific for the given LSP students (Hutchison and Waters, 1987, p. 54). It is, therefore, puzzling that many of us, LSP teachers, seem to base our courses on topics and vocabulary, rather than on the specific communicative situations identified by various stakeholders in the community of practice in question.

As our learners cross the border between adolescence and adulthood, so does course design at universities language centres require crossing the border between pedagogy and andragogy. This is why we connect LSP teaching with real life professional needs. Learners need to know why it is important to learn what the course and the teachers offer and see that every learning that takes place leads to a particular real situation or skill practice. Application of acquired knowledge to real-life situations is thus a powerful tool for intrinsic motivation of university students (see e.g. Knowles, 1990 in Caulfield, 2011).

This paper focusses on reasons why a team of teachers at Masaryk University Language Centre decided to abandon the traditional topic-based syllabus in order to focus on soft 
skills and life skills. Although I base the paper on our $^{1}$ experience with creating a soft-skills and life-skills based course for students of Legal English, it is intended as an inspiration for teachers of LSP in general. It gives examples of tasks, exercises and chained lesson plans any interested teacher can adapt to his or her learners' needs.

Our motivation to design a course for students of Legal English as soft-skill rather than topic-based was driven by the results of a detailed needs analysis carried out by the Masaryk University Language Centre staff (see Chovancová, 2013 and Chovancová, 2014) among recent faculty graduates and other in-service lawyers and law firm representatives. While faculty needs are defined in terms of legal topics we need to cover, and learning specific vocabulary and talking about law would be in line with novice students' expectations (Chovancová, 2014), in-service lawyers presented a very different view. When asked about what they needed English for in their current positions, inservice lawyers responded in terms of soft skills and real-life situations. Thus, we acquired a list of soft skills real life practitioners need to master in order to function in the target foreign language successfully.

The signal that, besides discussing specialized topics and specific or technical vocabulary, our graduates value especially their soft skills and life skills was so strong and explicit that we decided to change our approach and start building syllabi from a different perspective. We decided to move from topics as our starting point to life skills and from atomized language skills practice to task chaining leading to soft skills practice. The communicative skills that the respondents mentioned were using Skype, giving presentations, negotiating, chairing meetings, interviewing and mediating legal issues (Chovancová, 2013).

\section{TASK CHAINING IN LSP}

Task chaining is a useful method for any teacher who needs to prepare his or her own teaching material for LSP students. In this method, sub-skills are identified and reinforced in a student in a sequence to enable him or her to perform a more complex task. A document by Texas Statewide Leadership for Autism (TASN) provides us with a useful explanation: "chaining is an instructional strategy grounded in applied behaviour analysis (ABA) theory. Chaining is based on task analysis, whereby sub-behaviours are recognized as requirements for task mastery" ". Careful task analysis, however, is not reserved only for materials designed for learners with special needs. Task chaining is a practical method that is useful for teaching material development in general.

In tailoring LSP courses where the syllabus is based on target life skills and soft skills, we can take our inspiration in Task-based Language Learning Theory (TBLL) (see e.g. Richards and Rodgers, 2001, pp. 238-239). TBLL is mostly connected with fluency rather than accuracy practice as learners' goal is "message conveyance" (Ellis, 2003, p. 3 ). It is, however, our belief that tasks, i.e. "activities that call for primarily meaningfocus language use" (Ellis, 2003, p. 3) can be carefully blended with exercises, i.e.

\footnotetext{
${ }^{1}$ The course I am referring to is a result of co-operation between Masaryk University Language Centre staff based at the Faculty of Law who created most of the tasks and exercises I am basing my course on, and Kirby Vincent from University of Helsinki who co-operated on the negotiations case studies principles.

${ }^{2}$ (https://www.gvsu.edu/cms4/asset/64CB422A-ED08-43F0-F795CA9DE364B6BE/chaining.pdf)
} 
"activities that call for primarily form-focused language use" (Ellis, 2003, p. 3) in order to achieve a more balanced language learning outcome.

To achieve the right balance, we need to attempt to break these skills down into individual sub-skills not only from behavioural but also from linguistic point of view. We need to think of the individual steps students need to take towards the goal, define them and turn them into language-based activities. For illustration, we can call the simplest sub-skill oriented tasks Micro tasks, more complex activities they lead to Sub-macro tasks, and the final target activities Macro tasks. The following part of the paper will give an example of such an attempt.

\subsection{Chain analyses in negotiations for students of law}

As the in-service lawyers and law school graduates defined the previously mentioned "real needs" (Hutchison and Waters, 1987, p. 53), we were able to blend them with students' and faculty wishes and expectations. We prepared a course where the goals Macro tasks - are based on the communicative, soft and life skills identified mainly by the in-service lawyers. The legal topics required by the faculty are the content fillers of the activities leading to the goal. These topics generally define our Sub-macro tasks in the form of simple role-plays. Finally, expectations of the students mostly in terms of grammar and specialized vocabulary form the majority of the Micro tasks we chain in order to achieve the Macro tasks via the Sub-macro tasks.

I would like to illustrate the syllabus structuring with a case of practicing the skill of negotiating in legal English. We can break the Macro task down into three main Submacro tasks: soft skills the students practice (TBLL based), legal topics they discuss and modes of communication they use. These tasks are further broken down into basic Micro tasks (both tasks and exercises) that build up in terms of complexity and provide scaffolding for each other in order to raise students' intrinsic motivation to develop the particular skill.

Soft skills involve mainly mini-presentations of the legal topics in question and principles of communication and negotiation. Students also practice presenting arguments, giving speeches and giving constructive feedback. The aim is for students to practice their skills experientially. Activities are chained so that students first experience the skill, observe their peers actively in order to conceptualise and through giving feedback and self-reflecting, reflect as a whole class on the experience. The Macro task is achieved once they practice again and achieve the full Lewinian learning cycle (see e.g. Kolb et al, 2001, p. 229).

Micro tasks and exercises are chosen and created to practice language functions, levels of formality and politeness principles in English via language skills practice exercises developed with the use of texts and videos on relevant topics. These are traditional reading, listening, speaking and writing tasks complemented by vocabulary development and functional language exercises. These micro-tasks and exercises lead to simple role-plays designed to practice negotiations with their peers and reflect on their achievements in feedback giving (each class creates and agrees on their own feedback criteria), self-reflection and letter writing.

Having conceptualised and reflected on their performance, students can start concentrating on their Macro task, which is participating in negotiations. Students act as lawyers representing clients in Case studies based on civil law disputes. Students study 
the cases at home but time is also allotted for them to prepare for the final negotiation as a team in class.

Finally, they negotiate the aforementioned cases. The class concentrates on the individual cases, one by one. In our situation, there are usually three cases per class. Teams introduce themselves, the case, and their claims and positions, and negotiate in order to settle. The rest of the students in class play the role of active observers. Their task is to concentrate on how their peers negotiate and fill in a feedback form they created as an outcome of their previous discussion on negotiating principles, cooperation principles (Grice, 1991) and politeness principles (Leech, 1983). Once the parties reach a deal (or declare their negotiations failed), the whole class is invited to discuss the case, give peer-feedback and reflect on the success or failure of the negotiations. The next team is then asked to perform their negotiation.

In order to reinforce their self-reflection and learning experience, students are asked to write a report on the negotiation to a boss. This way, students experience, reflect on and conceptualise negotiating skills repeatedly. During this learning cycle, they are exposed to effective educational practices as defined by Umbach and Wawrzynski (2005), namely the use of active and collaborative learning techniques. Laurillard (2012, p. 57) states that "collaborative learning engages both social constructivism and experiential learning making it a powerful form of learning". We believe that the learning cycle based on repeated reflection leads to a sound learning experience.

An example of the chained skill based course that is run jointly between Masaryk University (Czech Republic) and the University of Helsinki (Finland) can be found in Hradilová and Vincent (in press). The course has its videoconferencing component where the class meets on several occasions with partners from abroad. In the following part of the article, I will give an example of a plan for such a soft-skill based course. The sessions have been planned for students of law, ranging from $\mathrm{B} 2$ to $\mathrm{C} 1$, with the majority being $\mathrm{B} 2$ level according to the Common European Framework of Reference for Languages.

\subsection{A chained plan for negotiations for students of law}

As mentioned above, we plan negotiations practice upon cases based on civil law. The introduction into the topic of civil law thus involves group brainstorming on the topic. Students brainstorm what they remember about the differences between civil and criminal procedures, stages of the procedures and typical vocabulary connected with the branch of law. A chain of exercises that further develops students understanding of the topic follows this activity. These are academic reading and listening exercises aimed at important vocabulary, collocations, prepositions, phrases, definitions and understanding the concepts and principles. The session continues by discussion on the qualities and behaviours a good legal representative in a civil case should display. Students brainstorm adjectives in small groups or pairs, and, as a class, create a mind map of 'dos and don'ts' a decent lawyer should follow. An exercise on formal versus informal language is introduced at this point. The session is closed by a simple role-play (a Sub-macro task) where a legal representative gives advice to a client. The role-play involves three students: one playing the role of a client, one a novice lawyer and one a senior lawyer who is a mentor to the novice one. The task for the senior lawyer is to observe the lawyer-client interview and take notes in order to give the novice lawyer feedback based on the mind map of qualities students created before (for examples of such activities see Bilová, Doupovcová and Chovancová, 2015). Once this activity finishes, students reflect on their experience of giving and receiving feedback and 
define basic advice to those giving and receiving feedback in future activities. As a homework, students write a well-structured formal letter of advice to the client, to which the teacher provides formative feedback.

The following session introduces the topic of negotiations. It is introduced via a video of a simple, brief negotiation where two people bargain to reach a deal. Students reflect on the video and brainstorm ideas regarding the basic rules of negotiations. This is followed by a vocabulary building exercise where students practice words typically associated with bargaining and negotiations. This exercise leads to a more complex listening exercise, where students watch a video featuring a negotiation that fails. Students' task is to analyse the reasons for the failure and suggest repair. It is complemented by exercises on functional language, e.g. grouping useful phrases according to their function in negotiating, and an exercise on indirectness and politeness in English, e.g. rewrite-the-rude-sentences-intopolite-ones-so-that-the-meaning-stays-the-same exercise. Later, they role-play the same situation, including the suggested changes, in order to settle. The session is concluded by a complex activity (Sub-macro task): students reflect on behaviour in negotiations and in groups, write a list of does and don'ts in negotiating. They use a shared document to perform the activity, so that the teacher can monitor their writing in real time. The teacher can then scroll down the document together with the whole class in order to rearrange students' thoughts into lists that will later serve the students in preparing for their final negotiation, as well as giving peer feedback on their colleagues' performance. The teacher turns these prompts into an observation and feedback form to be used for the final activity (a Macro task).

The following session can be devoted to student mini-presentations on topics relevant to the skill of negotiating. In pairs or small groups, students are asked to read a text and further research information on topics given by the teacher. As mentioned above, the topics related presentations cover relevant branches of civil law while the soft skills and linguistic (on the pragmatic level) topics concentrate on negotiating principles, cooperation principles (Grice, 1991) and politeness principles (Leech, 1983). At the end of the session, students negotiate their teams for the final case study negotiation. They receive their particular case study to take away and prepare at home.

The last session(s) in a row is/are fully devoted to the final negotiations. First, students are given the time in teams to do the final preparation for their group negotiations. The audience obtain the student-made feedback form to be filled in while listening to their peers, and then the process of case negotiations followed by peer-feedback and selfreflection starts rolling. The whole procedure is concluded by a general discussion on the experience and a writing task is set: write a formal structured report to your boss on the result of your negotiations.

\section{STUDENT FEEDBACK}

As a teacher, I became interested in how students perceive this change of teaching approach towards soft skills development, based on TBLL principles. Is there a difference students could notice? I decided to formulate two questions for a simple small-scale action research: 
1. Will students be aware of and appreciate the difference in the approach to LSP teaching?

2. Will students' motivation to learn be enhanced by a soft-skill based syllabus?

I have decided to test the soft-skill based syllabus approach on one group of students (12 students), keeping my other two groups in the topic based mode (31 students). The general content of the courses remained the same. Students, however, were given different objectives. The soft-skill based group (SBG) was led towards the final negotiations while the topic-based groups (TBG) were led towards covering the legal topics. This means that our example soft skill, i.e. negotiating, were embedded within the topic-based syllabus, while in the soft skill based syllabus, negotiating was the main goal whose content was filled by the topics.

In order to find answers to my research questions, I prepared an end-of-course questionnaire to be given to all the students. I was aware of the fact that the students could not answer my research questions directly as they lacked comparison with the other version of the course. This lack of reference to the other learning experience meant that I had to reformulate my questions for the purpose of the questionnaire and I had to invent a set of questions that would lead to a comparison of the sample with the control group. I formulated a set of neutral question that would not be leading for the students and received the most valuable answers to my original research questions mainly from students reactions to two questions on the following topic: Achievements in the course: could you describe your learning experience in detail?

The first prompt to give some interesting data were answers to a neutral, broad and open question: What did you learn? This general question encouraged students to think about the aims and goals of the course. They were able to provide a list of learning outcomes as they identified them. These differed, significantly, for the sample compared to the control group. Table 1 illustrates the distribution of answers.

Table 1 What did you learn?

\begin{tabular}{lrr}
\hline Student answers & TBG & SBG \\
\hline Topics (legal issues) & $16(52 \%)$ & 0 \\
Legal vocabulary & $14(45 \%)$ & $5(42 \%)$ \\
To negotiate and other soft skills & $7(23 \%)$ & $12(100 \%)$ \\
\hline
\end{tabular}

The difference in the focus of answers provided by the two groups of students is striking. While more than half students in the control (i.e. TBG) group mention legal topics, the same issue passes entirely unnoticed in the test (i.e. SBG) group. By contrast, negotiations and other soft skills are acknowledged and praised as useful by all the students in the test group, compared to less than a quarter of students who make the same observation in the control group. On the other hand, it is pleasing to see that vocabulary development does not seem to suffer from the change in the syllabus design, as the percentage of mention by the two groups of students is almost equal. These results promise a preliminary conclusion that students are aware of and appreciate the difference in the approach to LSP teaching.

The other research question was best answered by students' reaction to the following neutral, general and open question: How did you prepare for negotiations and why? It is my belief that by answering this question, students express their commitment to the final 
Macro task, reflect on the amount of work they put into preparation outside the classroom and why, thus indirectly giving evidence about their motivation to perform well in the final activity, and learn. I grouped the answers by the degree of student preparation and commitment. The following list offers an overview of students' typical answers.

Typical answers in SBG:

I read the handout and researched the web $(42 \%)$

I studied the materials together with my group (group work, teamwork) (58\%)

Typical answers in TBG:

I did not prepare at all $(28 \%)$

I briefly read the handout (34\%)

I read the handout and prepared arguments (38\%)

The interpretation of the data seems to be straightforward in this case. All the test group students claim a thorough preparation for the final Macro task, mentioning tightening the relations in the group, not wanting to be surprised or caught by the opponents unprepared or loosing face in front of the others as a reason. This is, however, true of only $38 \%$ of students in the control group, with the rest confessing to only minimal or no preparation at all. As to the question why?, the TBG commented on their non-preparedness only e.g. laziness or strong belief in improvisation.

Students' answers are further supported by the fact that while students in the test group need a full session to negotiate, provide feedback and reflect on only one of the cases, the same amount of time is sufficient to discuss all the three cases in the control group. A tentative conclusion can be drawn that the less prepared students run out of arguments earlier and are inclined to finish negotiations fast. The better-prepared students, on the other hand, have bigger intrinsic (I have put time into preparation) as well as extrinsic (I do not want to lose face) motivation to perform as successful negotiators. The form of learning in the test group is therefore more powerful.

Although this research is only small-scale and needs to be developed further with future groups, the preliminary results are promising. It seems that the answers to both of the research questions are 'yes'.

\section{CONCLUSION}

The paper offers a description of a beginning of a journey towards practicing soft skills as the basic principle of an LSP course. It illustrates an experiment in changing the direction of a language teacher; of turning a topic based LSP syllabus into a soft skill based one. It shows how this practice leads to useful soft skills development where topics serve the purpose of soft-skill practice fillers and vocabulary building is a natural byproduct of the activities.

Student feedback illustrates how students appreciate the difference in the approach to LSP learning. The action research that was carried out on a small sample of students indicates that while the same percentage of students appreciate specific vocabulary development in both topic based and soft skill based courses, their appreciation of soft skills grows dramatically if the course is a soft skill based one. It is, therefore, important that we maintain the balance between soft skill practice based on TBLL fluency development, 
indicated as important by our in-service respondents, while paying attention to accuracy, vocabulary building and language practice. These are the expectations of our students, which we need to react to in order to satisfy their needs.

Preliminary results also indicate that basing learning on soft-skill practice may positively influence students' motivation to learn. All the students in the soft skill based group, unlike their topic based group peers, put considerable effort into home preparation, claiming to have not only studied the materials but also further researching and group discussing the cases outside the classroom.

Further action research must, however, be carried out on future groups in order to obtain a more convincing number of answers to the questions asked by the teacher. We expected positive answers and reaction to the test syllabus as the activities are real-lifelike, involve popular role-plays and make the sessions even more communicative. Students' role is active and pro-active, and their activity leads to a clear end-point in the form of a final performance, i.e. a Macro task, which serves well to building student motivation to learn. It is, however, important that we do not get side-tracked by the allure of the very convincing extreme data in percentages, receiving zero on the one hand and a hundred percent on the other, as the absolute numbers we work with are petit. Therefore, we will keep asking the same questions to our future groups in order to give our results a better chance to hold up to scientific scrutiny.

Moreover, the teachers involved in the process need to revise the other questions in the questionnaire which did not lead to any interesting findings in terms of student motivation and learning processes. We are also likely to open more questions and doubts on the topic in the future. We need to know if and what influence the videoconferencing component has on student motivation, since our questionnaire did not bring an explicit answer to the significance of this factor. Finally, we will be interested to know if students' preferred learning styles correlate with the methods we use and if we can find a possible way for students to choose a learning style in the courses of legal English.

\section{REFERENCES}

Bilová, Š., Doupovcová, R. \& Chovancová, B. (2015). Innovative Activities in Learning English. Brno: Language Centre, Masaryk University. https://impact.cjv.muni.cz/wpcontent/uploads/2015/02/PRF-Innovative-Activities-in-Legal-English1.pdf (accessed 27 April 2018).

Caulfield, J. (2011). How to design and teach a hybrid course. Sterling, Virginia: Stylus Publishing.

Chovancová, B. (2013). From Classroom to Courtroom: Preparing legal English students for the real world. In Vystrčilová, R. Právní jazyk - od teorie k praxi (Legal Language - from Theory to Practice). Olomouc: Univerzita Palackého, pp. 69-76.

Chovancová, B. (2014). Needs analysis and ESP course design: Self-perception of language needs among pre-service students. Studies in Logic, Grammar and Rhetoric. Bialystok: University of Bialystok, Vol. 38, No. 51, pp. 43-57.

Ellis, R. (2003). Task-based Language Learning and Teaching. Oxford, England: Oxford University Press.

Grice, P. (1991). Studies in the Way of Words. Cambridge, Massachusetts, London, England: Harvard University Press. 
Hutchinson, T. \& Waters, A. (1987). English for Specific Purposes: A Learning Centred Approach. Cambridge: Cambridge University Press.

Hradilová, A. \& Vincent, K. (In press). Daring to Videoconference: Ideas for Teachers. In Štěpánek, L., Sedláčková, K. \& Byrne, N. (Eds.) (in press). Videoconferencing in University Language Education. Brno, Czech Republic: Munipress.

Knowles, M.S. (1990). The Adult Learner: A Neglected Species. Houston: Gulf.

Kolb, D. A., Boyatzis, R. E. \& Mainemelis, C. (2001). Experiential Learning Theory: Previous research and new directions. In Sternberg, R. J. \& Zhang, L. (Eds.) Perspectives on Thinking, Learning, and Cognitive Styles. New York, London: Routledge.

Laurillard, D. (2012). Teaching as a Design Science: Building Pedagogical Patterns for Learning and Technology. New York: Routledge.

Leech, G. N. (1983). Principles of Pragmatics. Harlow: Longman.

Richards, J. C., Rodgers, T. S. (2001). Approaches and Methods in Language Teaching. Cambridge, England: Cambridge University Press, pp. 223-239.

Štěpánek, L., Sedláčková, K. \& Byrne, N. (Eds.) (in press). Videoconferencing in University Language Education. Brno, Czech Republic: Munipress.

Texas Statewide Leadership for Autism. Chaining. (https://www.gvsu.edu/cms4/ asset/64CB422A-ED08-43F0-F795CA9DE364B6BE/chaining.pdf) (accessed 13 April 2018).

Umbach, P.D., \& Wawrzynski, M. R. (2005). Faculty do matter: The role of college faculty in student learning and engagement. Research in Higher Education, 46(2), pp. 153-184.

Vystrčilová, R. (2013). Právní jazyk - od teorie k praxi (Legal Language - from Theory to Practice). Olomouc: Univerzita Palackého. 